\title{
BIOGEOGRAPHY OF INVERTEBRATES IN hanging Gardens of the Colorado Plateau
}

\author{
NANCY L. STANTON $\bullet$ STEVEN W. BUSKIRK $\bullet$ JAMES F. FOWLER \\ DEPARTMENT OF ZOOLOGY AND PHYSIOLOGY \\ UNIVERSITY OF WYOMING $\bullet$ LARAMIE
}

\section{- INTRODUCTION}

Hanging gardens are relatively small, isolated mesophytic communities surrounded by the xeric environment of canyon walls in the entrenched dendritic drainage pattern of the Colorado Plateau (Welsh 1989a, Malanson 1980, Welsh and Toft 1972). Various sandstone formations such as the Navajo in Zion National Park serve as aquifers which produce permanent seeps or springs when underlain by impervious layers (Welsh and Toft 1972). These reliable sources of water, and the associated processes of erosion and sedimentation, allow the formation of biotic communities that starkly contrast with the surrounding desert. Several endemic plant species have been found in Utah hanging garden surveys (Welsh 1989b, Loope 1977, Welsh and Toft 1972) and Dinosaur National Monument ( $T$. Naumann, personal comm.). Virtually nothing is known about the invertebrate fauna. Our specific research objectives are to (1) survey the plant and invertebrate animal communities of hanging gardens in Zion National Park (ZION) and Glen Canyon National Recreation Area (GLCA), (2) map the geographic distribution of the endemics identified and determine levels of endemism within and among parks; (3) determine levels of similarity between each sampled hanging garden plant and insect community, and to (4) determine similarities among plant communities and among insect communities across gardens.

\section{FIELD METHODS}

Most of the hanging gardens we sampled were chosen during a reconnaissance trip to ZION and GLCA on May 14-18, 1991. We centered our work on the larger distinct hanging gardens which Welsh (1984, 1989a, 1989b) and Tuhy and MacMahon (1988) had previously surveyed for plant species during prior NPS-sponsored research. Thus we were able to focus on measuring the community importance of plant species in these gardens, especially the endemics; to expand to nearby smaller hanging gardens; and to increase our effort on invertebrate surveys.

Each hanging garden was visually separated into the following microhabitats: wet walls/floors, ledges, and colluvial soils below ledges. Wet walls were obviously vertical whereas wet floors were covered with a thin sheet flow of water. Both were dominated by prokaryotic and protistan communities. Ledges were of sufficient width and length to support linear plant communities. Most of the vascular plant communities were found on colluvial soils which develop just downslope of ledges or on the talus/scree underneath an alcove. Herbaceous vegetation was systematically sampled by Daubenmire frames to estimate percent canopy cover by species. Voucher specimens were collected for each species. Systematically placed line transects were also used in GLCA when woody plants were an important 
component of the community. For the smallest hanging gardens, only plant species lists were compiled.

Sampling intensity for insects was hierarchically scaled with hanging garden size. For the largest hanging gardens, such as Upper Three Garden at GLCA or Grotto Hanging Garden at ZION, we used pitfall and malaise traps for insects as well as general sweep netting of the vegetation. Off-garden controls were set on dry slopes for malaise and pitfall traps. We also collected flower feeders and pollinators when plants were blooming. Insects were collected from wet walls and floors by hand or aspirator. Malaise traps were set only on the largest hanging gardens in order to minimize the collection of-off site insects. However, pitfall traps were placed on all but the smallest hanging gardens.

Seasonal effects will be examined from plant and insect data collected in June, July, and August from ZION's two largest hanging gardens: Upper Emerald Hanging Garden and Grotto Hanging Garden. These gardens were completely sampled each month. Small mammal presence-absence data were collected on three hanging gardens in both ZION and GLCA.

\section{- RESUlts AND DisCUSSION}

Within the Coleoptera (beetles), the Carabidae and the aquatic Gyrinidae and Dytiscidae (Table 1) contain the most specimens. The best represented families of Apoidea (bees) are the Halictidae and the Apidae. Among the Hemiptera (true bugs), the aquatic families Veliidae and Gerridae and the terrestrial family Miridae are the best represented by collected specimens (Table 1).

In GLCA and ZION, many hanging gardens appear to be located at the contact between the Navajo sandstone and the Kayenta formation, at approximate elevations of 1248-1260 and 1350-1410 m respectively. These gardens straddle the contact and have distinct geomorphic microhabitats. The wet backwall (and hanging wall under an alcove) are in the cliff forming Navajo sandstone, whereas the ledges and colluvial soil slopes develop in the siltstone and mudstone layers of the Kayenta.

Over 400 plant specimens were collected as vouchers for distribution and community data. At this time, species appear to be in agreement with Welsh's $(1984,1989 a)$ reports to ZION and GLCA.

Table 1. Preliminary trends in insect family richness and importance for three selected taxa from hanging gardens in ZION and GLCA. ( ) indicate number of specimens.

\begin{tabular}{lll}
\hline Coloeptera & Hemiptera & Apoidea \\
\hline Chrysomelidae (13) & Gerridae (26) & Halictidae (26) \\
Dytiscidae (18) & Cicadidae (1) & Megae (46) \\
Gyrinidae (86) & Pentatomidae (8) & \\
Tenebrionidae (7) & Miridae (15) & \\
Carabidae (16) & Rhopalidae (5) \\
Leiodidae (10) & Veliidae (29) & \\
Scarabaeidae (11) & Hebridae (4) & \\
Lampyridae (11) & Lygaeidae (1) & \\
Scirtidae (1) & Reduviidae (1) & \\
Buprestidae (1) & Dipsocoridae? (1) & \\
Pselaphidae (1) & Nabidae (1) \\
Heteroceridae (1) & Notonectidae (1) & \\
Lycidae (2) & & \\
Elateridae (12) & & \\
Coryophidae (2) & & \\
Hydrophilidae (3) & & \\
Curculionidae (1) & & \\
\end{tabular}


Insect collections are currently being processed and identified to family prior to shipment to the USDA Bee Laboratory at Utah State University and the Systematic Entomology Laboratory at Oregon State for species identification. Most of the sweep netted, hand, and flower pollinator/feeder collections have been processed and shipped for identification. Over 1400 insects have been pinned thus far.

The first priority for the remainder of the reporting period is to identify the pressed plant specimens and to process the pitfall and malaise trap insect collections. Analyses of vegetation ecology data and plant and insect biogeographic distribution patterns will follow. The results of these analyses will then be used to refine our field sampling techniques for next season. We also plan to evaluate Welsh and Toft's (1972) classification of hanging gardens into three types: alcove (with five developmental stages), windowblind, and terrace. So far, we have found this classification difficult to interpret and apply, even though it has descriptive value. An attempt will be made to incorporate surface drainage patterns, geologic structure, and erosional features into Welsh's system, or to construct a new one.

\section{$\checkmark \quad$ ACKNOWLEDGEMENTS}

Our thanks go to Rick Harris (GLCA), Vic Vieira (ZION), and Frank Hayes (ZION) for access to NPS reports and logistical support. Thanks also go to our technicians Cathleen May and Jon Hak for their dedication to the project.

\section{- LITERATURE CITED}

Loope, W. L. 1977. Relationships of vegetation to environment in Canyonlands National Park. Unpubl. Ph.D. Diss. Utah State University.

Malanson, G. P. 1980. Habitat and plant distribution in hanging gardens of the narrows, Zion National Park, Utah. Gt. Basin Nat. 40:178182.

Tuhy, J. S., and J. A. MacMahon. 1988. Vegetation and relict communities of Glen Canyon National Recreational Area, Final Report, NPS contract CX1200-6-B076.

Welsh, S. L. 1984. Flora of Glen Canyon National Recreation Area, Unpub. mss. Glen Canyon National Recreation Area.

1989a. Hanging gardens of Zion National Park, Final report NPS contract CX1590-70001.

1989b. On the distribution of Utah's hanging gardens. Gt. Basin Nat. 49:1-30.

and C. A. Toft. 1972. Biotic communities of hanging gardens in southeastern Utah. Nat. Geo. Soc. Res. Report 13:663-681. 